\title{
Pulmonary artery pressure limits exercise capacity at high altitude
}

\author{
R. Naeije*, S. Huez ${ }^{\#}$, M. Lamotte ${ }^{\#}$, K. Retailleau ${ }^{\top}$, S. Neupane ${ }^{+}$, \\ D. Abramowicz ${ }^{\S}$ and V. Faoro*
}

ABSTRACT: Altitude exposure is associated with decreased exercise capacity and increased pulmonary vascular resistance (PVR).

Echocardiographic measurements of pulmonary haemodynamics and a cardiopulmonary exercise test were performed in 13 healthy subjects at sea level, in normoxia and during acute hypoxic breathing (1 h, 12\% oxygen in nitrogen), and in 22 healthy subjects after acclimatisation to an altitude of $5,050 \mathrm{~m}$. The measurements were obtained after randomisation, double-blinded to the intake of placebo or the endothelin A receptor blocker sitaxsentan (100 $\mathrm{mg}^{-\mathrm{day}^{-1}}$ for $^{-}$ 7 days). Blood and urine were sampled for renal function measurements.

Normobaric as well as hypobaric hypoxia increased PVR and decreased maximum workload and oxygen uptake $\left(V^{\prime} \mathrm{O}_{2}\right.$, max). Sitaxsentan decreased PVR in acute and chronic hypoxia (both $p<0.001)$, and partly restored $V^{\prime} \mathrm{O}_{2}$, max, by $30 \%$ in acute hypoxia $(p<0.001)$ and $10 \%$ in chronic hypoxia $(p<0.05)$. Sitaxsentan-induced changes in PVR and $V^{\prime} O_{2}$, max were correlated $(p=0.01)$. Hypoxia decreased glomerular filtration rate and free water clearance, and increased fractional sodium excretion. These indices of renal function were unaffected by sitaxsentan intake.

Selective endothelin A receptor blockade with sitaxsentan improves mild pulmonary hypertension and restores exercise capacity without adverse effects on renal function in hypoxic normal subjects.

KEYWORDS: Hypoxia, maximal oxygen uptake, pulmonary vascular resistance, renal function, sitaxentan

$\mathrm{H}$ igh-altitude exposure is associated with a decreased aerobic exercise capacity, in relation to both a decrease in arterial oxygen content and a limitation in maximal cardiac output [1]. With acclimatisation, the arterial oxygen content may be restored to sealevel values because of an increased haemoglobin concentration, but maximal cardiac output remains low [2]. The decrease in maximal cardiac output at altitude has been tentatively explained by the combined effects of decreased blood volume, hypocapnia, increased viscosity of the blood, autonomic nervous system changes or reduced myocardial function, but is probably accounted for by an altered coupling of convectional and diffusional oxygen transport systems [3]. An additional factor might be a limitation in right ventricular flow output secondary to hypoxic pulmonary hypertension. An improvement in maximal workload and maximal oxygen uptake $\left(V^{\prime} \mathrm{O}_{2}\right.$, max $)$ together with a decrease in pulmonary artery pressure $(P \mathrm{pa})$ has indeed been reported after the intake of sildenafil in hypoxic healthy volunteers $[4,5]$. More recently, there has been report of decreased $P$ pa and improved $V^{\prime} \mathrm{O}_{2}$, max in subjects susceptible to high-altitude pulmonary oedema taking dexamethasone before altitude exposure [6]. However, improved exercise capacity in these studies could not unequivocally be ascribed to associated inhibition of hypoxic pulmonary vasoconstriction because of additional effects, including a variable improvement in arterial $\mathrm{O}_{2}$ content [4-7].

We recently reported an improved $V^{\prime} \mathrm{O}_{2}$, max specifically related to a decreased $P$ pa by the administration of the nonselective endothelin receptor antagonist bosentan in acutely hypoxic normal subjects [8]. In the present study, we tested the hypothesis that inhibition of hypoxic pulmonary vasoconstriction by the selective endothelin A receptor antagonist sitaxsentan [9] would allow for a persistent improvement in aerobic exercise in normal subjects at high altitudes. We also investigated the effects of sitaxsentan on renal function, as a decreased free water clearance has been reported after the intake of bosentan at high altitudes [10].

\section{AFFILIATIONS}

*Laboratory of Physiology, Faculty of Medicine, Free University,

"Dept of Cardiology,

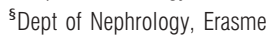

University Hospital, Brussels, and

"Dept of Cardiology, CHU Charleroi

Hospital, Charleroi, Belgium.

${ }^{+}$Institute of Medicine, University of

Kathmandu, Kathmandu, Nepal.

CORRESPONDENCE

R. Naeije

Dept of Physiology

Erasme Campus CP 604

808 Lennik road

B-1070 Brussels

Belgium

E-mail: rnaeije@ulb.ac.be

Received:

Feb 122010

Accepted after revision:

March 242010

First published online:

April 022010 


\section{METHODS \\ Subjects}

A total of 30 healthy subjects, 15 males and 15 females aged 2359 yrs (mean $35 \mathrm{yrs}$ ), with a mean \pm SE height of $173 \pm 2 \mathrm{~cm}$ and weight of $66 \pm 2 \mathrm{~kg}$, gave informed consent to the study, which was approved by the Ethical Committee of the Erasme University Hospital (Brussels, Belgium).

\section{Protocol design}

Measurements of heart rate (HR), blood pressure (BP) and transcutaneous arterial $\mathrm{O}_{2}$ saturation measured by pulse oximetry $\left(\mathrm{Sp}, \mathrm{O}_{2}\right)$ were taken in all subjects. Clinical examinations were performed at sea level and at high altitude.

Blood and urine were sampled in 17 subjects at sea level and 22 subjects at high altitude for renal function measurements.

At sea level, 22 of the subjects underwent Doppler echocardiography at rest to estimate $P$ pa, cardiac output and right ventricular function, and an incremental cycle ergometer cardiopulmonary exercise test (CPET) with measurements of ventilatory variables, workload, $\mathrm{BP}, \mathrm{HR}$ and $\mathrm{Sp}, \mathrm{O}_{2}$ to measure aerobic exercise capacity.

The normobaric normoxic and hypoxic measurements were repeated in 13 subjects after a 1-week treatment with sitaxsentan $\left(100 \mathrm{mg} \cdot \mathrm{day}^{-1}\right)$ or a placebo, either in normoxia, or after $1 \mathrm{~h}$ breathing a fraction of inspired $\mathrm{O}_{2}\left(\mathrm{FI}, \mathrm{O}_{2}\right)$ of $12 \%$ from a pre-mixed tank of $\mathrm{O}_{2}$ in nitrogen. The subjects were equipped with tightly fitted face masks to breathe either room air or the low $-\mathrm{O}_{2}$ mixture. The $\mathrm{FI}_{1} \mathrm{O}_{2}$ of 0.12 corresponded approximately to the inspired partial pressure of $\mathrm{O}_{2}$ at an altitude of 4,500 m. Sea-level measurements were performed according to a prospective, randomised, controlled cross-over study design. Thus, 13 subjects had four echocardiograms and CPET at sea level, each in one of the following conditions: normoxia-placebo, normoxia-sitaxsentan, hypoxia-placebo, hypoxia-sitaxsentan.

Under the hypobaric hypoxic condition, 22 subjects had two echocardiograms and CPET at high altitude at baseline and 1 week later, after intake of either a placebo or sitaxsentan.

The sampling of blood and urine for renal function measurements took place at 08:00 h only in normoxia at sea level in 17 subjects, and at the same hour at high altitude in 22 subjects. The urine collections covered the previous $24 \mathrm{~h}$ at sea level, and $2 \mathrm{~h}$ at altitude. The subjects were instructed to observe their usual diets and schedules, and to refrain from coffee consumption and cigarette smoking.

The normobaric normoxic and hypoxic measurements were performed in Brussels, at sea-level altitude. The hypobaric hypoxic measurements were obtained at the Pyramid International Laboratory Observatory at 5,050 m, in the Khumbu area of the Sagamartha National Park (Nepal). This is reached after a 1-week hike at progressively increased altitudes following aeroplane transportation from Kathmandu (Nepal), at $\sim 800 \mathrm{~m}$, to Lukla (Nepal), at 2,800 m. The hike is easy-going and usually allows for a satisfactory acclimatisation. Once at the Pyramid hut, the subjects rested or walked about in the surrounding area, avoiding strenuous exercise activities. Meals were served by the local staff, and intake of water or hot lemon was allowed ad libitum. Altitude measurements were obtained at baseline and repeated after 1 week of sitaxsentan $(100 \mathrm{mg})$ or a placebo given in a prospective, randomised, controlled, double-blind fashion. Sitaxsentan was taken once daily for 7 days to achieve steady state of plasma levels [9].

\section{Clinical measurements}

BP was measured by sphygmomanometry, with mean pressure calculated as diastolic pressure plus one-third of the pulse pressure. A three-lead ECG was used to measure HR. $S \mathrm{p}, \mathrm{O}_{2}$ was measured by ear-lobe pulse oximetry (Konica Minolta Pulsox-3i; Konica Minolta Sensing, Osaka, Japan). Attention was paid to local temperature and quality of the signal, especially during exercise, as it is known that accuracy and precision of pulse oximetry at exercise may be decreased by local perfusion [11]. Haemoglobin concentration was measured at sea level and at 5,050 $\mathrm{m}$ in 17 of the subjects. The presence of acute mountain sickness in hypoxia was assessed by the use of the Lake Louise consensus scoring system [12].

\section{Echocardiography}

The Doppler echocardiographic measurements were performed with a Vivid 7 ultrasound system at sea level and its Vivid i portable version at altitude (GE Ultrasound, Horten, Norway). Cardiac output (Q) was estimated from left ventricular outflow tract cross-sectional area and pulsed Doppler velocity-time integral measurements [13]. Systolic $P$ pa was estimated from a transtricuspid gradient calculated from the maximum velocity of continuous Doppler tricuspid regurgitation, added to a fixed value of $5 \mathrm{mmHg}$ attributed to right atrial pressure [14]. Pulmonary vascular resistance (PVR) was calculated as mean $P_{\text {pa }}\left(\bar{P}_{\text {pa }}\right) / \mathrm{Q}$, with $\bar{P}_{\text {pa calculated as }} 0.61 \times$ systolic $P$ pa +2 [15]. Systolic right ventricular function was estimated by M-mode measurement of the tricuspid annular plane systolic excursion (TAPSE) [16]. A composite index of right ventricular function was calculated as the ratio of the sum of isovolumic contraction and relaxation times to the ejection time, as previously proposed by TEI et al. [17]. The echocardiographic recordings were read blind and in duplicate.

\section{CPET}

The CPET was performed in an erect position on an electronically braked cycle ergometer (Monark Ergomedic 818 E; Monark, Vansbro, Sweden) with breath-by-breath measurements, through a tightly fitted face mask, of minute ventilation $\left(V^{\prime} \mathrm{E}\right), \mathrm{O}_{2}$ uptake $\left(V^{\prime} \mathrm{O}_{2}\right)$, and $\mathrm{CO}_{2}$ output $\left(V^{\prime} \mathrm{CO}_{2}\right)$ using a cardiopulonary exercise system (Oxycon Mobile ${ }_{\circledR}$; Jaeger, Hoechberg, Germany). The work rate was increased by 15-30 W. $\mathrm{min}^{-1}$ (according to previously known exercise capacity and predicted decrease by $\sim 35 \%$ at high altitude so that the test would last 10-12 min) until exhaustion [18]. Maximal $V^{\prime} \mathrm{O}_{2}\left(V^{\prime} \mathrm{O}_{2}\right.$, max $)$ was defined as the $V^{\prime} \mathrm{O}_{2}$ measured during the last $20 \mathrm{~s}$ of peak exercise. The respiratory exchange ratio (RER) was calculated as $V^{\prime} \mathrm{CO}_{2} / V^{\prime} \mathrm{O}_{2}$, and $\mathrm{O}_{2}$ pulse as $V^{\prime} \mathrm{O}_{2} / \mathrm{HR}$. The ventilatory equivalents for $\mathrm{CO}_{2}\left(V^{\prime} \mathrm{E} / V^{\prime} \mathrm{CO}_{2}\right)$ were calculated by dividing $V^{\prime} \mathrm{E}$ by $V^{\prime} \mathrm{CO}_{2}$. The anaerobic threshold was estimated by the V-slope method [18].

\section{Renal function}

Blood samples and urine were immediately put on ice and sent to the routine hospital laboratory, located at sea level. At altitude, blood was centrifuged, and plasma and urine samples 


\begin{tabular}{|c|c|c|c|c|}
\hline $\begin{array}{l}\text { Effect } \\
\text { oxyge } \\
\text { hypox }\end{array}$ & $\begin{array}{l}\text { ts of sitax } \\
\text { en saturati } \\
\text { xia in } 13 n\end{array}$ & ion in norr & oxia and & $\begin{array}{l}\text { cs and } \\
\text { acute } \\
\text { vel at rest }\end{array}$ \\
\hline \multirow[t]{2}{*}{ Variables } & \multicolumn{2}{|c|}{ Normoxia } & \multicolumn{2}{|c|}{ Acute hypoxia ${ }^{\#}$} \\
\hline & Placebo & Sitaxsentan & Placebo & Sitaxsentan \\
\hline LL score & & & $2 \pm 0.5$ & $4 \pm 1.5$ \\
\hline${\mathrm{Sp}, \mathrm{O}_{2}}_{\mathrm{L}}$ & $98 \pm 0.3$ & $98 \pm 0.2$ & $72 \pm 2^{\circ}$ & $73 \pm 3^{\circ}$ \\
\hline BP mmHg & $87 \pm 2$ & $82 \pm 2^{+}$ & $83 \pm 2$ & $81 \pm 2$ \\
\hline HR beats $\cdot \min ^{-1}$ & $57 \pm 3$ & $60 \pm 4$ & $69 \pm 5^{\S}$ & $69 \pm 5^{\S}$ \\
\hline$Q \mathbf{L} \cdot \min ^{-1}$ & $4.7 \pm 0.3$ & $5.0 \pm 0.4$ & $6.2 \pm 0.5^{\S}$ & $6.6 \pm 0.6^{\S}$ \\
\hline Systolic Ppa mmHg & $23 \pm 1$ & $23 \pm 2$ & $37 \pm 2$ & $28 \pm 2^{\S}, f$ \\
\hline $\bar{P}_{\text {pa }} \mathrm{mmHg}$ & $16 \pm 1$ & $16 \pm 1$ & $25 \pm 2^{\circ}$ & $19 \pm 1^{\S}, f$ \\
\hline PVR $\mathrm{mmHg} \cdot \mathrm{L}^{-1} \cdot \mathrm{min}^{-1}$ & $3.5 \pm 0.2$ & $3.4 \pm 0.3$ & $4.2 \pm 0.3^{\S}$ & $3.1 \pm 0.3 f$ \\
\hline Tei index & $0.21 \pm 0.05$ & $0.18 \pm 0.03$ & $0.30 \pm 0.05$ & $0.19 \pm 0.03^{+}$ \\
\hline TAPSE $\mathrm{cm}$ & $3.1 \pm 0.2$ & $3.1 \pm 0.1$ & $3.0 \pm 0.1$ & $3.0 \pm 0.1$ \\
\hline \multicolumn{5}{|c|}{ 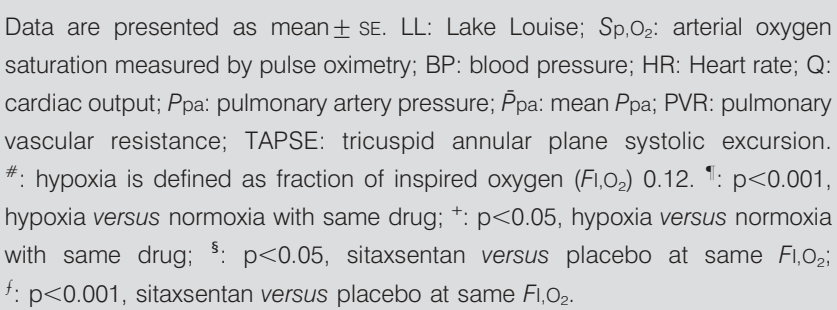 } \\
\hline
\end{tabular}

were frozen and stored at $-20^{\circ} \mathrm{C}$. Plasma and urine were assayed for electrolytes with an ion-sensitive electrode (Instrumentation Beckmann Astra, Brea, CA, USA). Uric acid was measured by the uricase method and creatinine by the Jaffé reaction (Instrumentation Beckmann Astra). Plasma and urine uric acid, and osmolalities were also measured. Glomerular filtration rate (GFR) was estimated from the clearance of endogenous creatinine $\left(\mathrm{C}_{\mathrm{cr}}\right)$. Free water clearance $\left(\mathrm{CH}_{2} \mathrm{O}\right)$ was calculated by the difference between urine volume flow and osmolar clearance. Fractional excretions of uric acid and sodium were calculated by the ratios of uric acid and sodium to creatinine clearances.

\section{Statistics}

Results are presented as mean \pm SE. The statistical analysis consisted of a repeated measures ANOVA. When the F ratio of the ANOVA reached a critical value of $p<0.05$ critical value, paired or unpaired t-tests were applied to compare specific situations [19]. Correlations were calculated by linear regression analysis.

\section{RESULTS \\ Effects of acute normobaric hypoxia on CPET and haemodynamics}

Exposure to acute normobaric hypoxia was well tolerated, except for transient mild headache in some subjects, such that the Lake Louise score remained at $2 \pm 1$. Hypoxia decreased $S_{\mathrm{p}, \mathrm{O}_{2}}$ and increased Q, HR, systolic $P$ pa, $\bar{P}_{\mathrm{pa}}$ and PVR, while BP remained unchanged (table 1 ). Hypoxia affected CPET measurements by decreasing $V^{\prime} \mathrm{O}_{2}$, max, workload, $V^{\prime}$ E, $\mathrm{HR}$ and $\mathrm{O}_{2}$ pulse, decreasing $V^{\prime} \mathrm{O}_{2}$ at the anaerobic threshold, decreasing $\mathrm{Sp}, \mathrm{O}_{2}$ at maximum exercise and increasing $V^{\prime} \mathrm{E} / V^{\prime} \mathrm{CO}_{2}$ at the

\begin{tabular}{|c|c|c|c|c|}
\hline \multirow[t]{2}{*}{ Variables } & \multicolumn{2}{|c|}{ Normoxia } & \multicolumn{2}{|c|}{ Acute hypoxia ${ }^{\#}$} \\
\hline & Placebo & Sitaxsentan & Placebo & Sitaxsentan \\
\hline Workload max W & $280 \pm 18$ & $288 \pm 18$ & $179 \pm 14^{\circ}$ & $196 \pm 16^{+}$ \\
\hline $\begin{array}{l}V^{\prime} \mathrm{O}_{2}, \max \\
\mathrm{mL} \cdot \mathrm{kg}^{-1} \cdot \mathrm{min}^{-1}\end{array}$ & $47 \pm 2$ & $48 \pm 2$ & $32 \pm 2^{\prime}$ & $35 \pm 2^{5,9}$ \\
\hline$V^{\prime} E \max L \cdot \min ^{-1}$ & $114 \pm 7$ & $118 \pm 7$ & $95 \pm 7^{f}$ & $96 \pm 7^{f}$ \\
\hline RER max & $1.21 \pm 0.02$ & $1.21 \pm 0.02$ & $1.26 \pm 0.03$ & $1.26 \pm 0.02$ \\
\hline HR max beats $\min ^{-1}$ & $177 \pm 6$ & $181 \pm 3$ & $166 \pm 6^{f}$ & $168 \pm 6^{f}$ \\
\hline $\mathrm{O}_{2}$ pulse $\mathrm{mL} \cdot$ beat $^{-1}$ & $18 \pm 1$ & $18 \pm 1$ & $13 \pm 1^{\circ}$ & $14 \pm 1^{\bullet}$ \\
\hline $\begin{array}{l}V^{\prime} \mathrm{O}_{2} \text { at } A T \\
\mathrm{~mL} \cdot \mathrm{kg}^{-1} \cdot \mathrm{min}^{-1}\end{array}$ & $35 \pm 2$ & $35 \pm 2$ & $22 \pm 2$ & $23 \pm 3^{\circ}$ \\
\hline$V^{\prime} E / V^{\prime} \mathrm{CO}_{2}$ at $A T$ & $30 \pm 1$ & $30 \pm 1$ & $33 \pm 2$ & $33 \pm 1^{\circ}$ \\
\hline Exercise $\mathrm{Sp}_{\mathrm{p}, \mathrm{O}_{2}} \%$ & $92 \pm 1$ & $92 \pm 1$ & $78 \pm 2^{\circ}$ & $79 \pm 1^{\circ}$ \\
\hline
\end{tabular}

Data is presented as mean $\pm \mathrm{SE}$. max: maximum; $\mathrm{V}^{\prime} \mathrm{O}_{2}$, max: maximum oxygen uptake; V'E: minute ventilation; RER: respiratory exchange ratio; HR: heart rate; AT: anaerobic threshold; $V^{\prime} \mathrm{CO}_{2}: \mathrm{CO}_{2}$ output; $\mathrm{Sp}, \mathrm{O}_{2}$ : arterial oxygen saturation measured by pulse oximetry. ${ }^{*}$ : hypoxia is defined as fraction of inspired oxygen $\left(\mathrm{F} 1, \mathrm{O}_{2}\right)$ 0.12. ${ }^{\top}: \mathrm{p}<0.001$, hypoxia versus normoxia with same drug; ${ }^{+} ; \mathrm{p}<0.001$ sitaxsentan versus placebo at same $\mathrm{FI}_{1}, \mathrm{O}_{2} ;{ }^{\text {s: }} \mathrm{p}<0.01$, sitaxsentan versus placebo at same $\mathrm{FI}, \mathrm{O}_{2} ;{ }^{f}: \mathrm{p}<0.01$, hypoxia versus normoxia with same drug

anaerobic threshold (table 2). Maximum RER was not different in hypoxia compared to normoxia.

\section{Effects of chronic hypobaric hypoxia on CPET and haemodynamics}

Exposure to the altitude of $5,050 \mathrm{~m}$ was well tolerated. Haemoglobin concentration measured in 17 subjects increased from $14.2 \pm 0.2 \mathrm{~g} \cdot \mathrm{dL}^{-1}$ at sea level to $14.9 \pm 0.4 \mathrm{~g} \cdot \mathrm{dL}^{-1}$ at high altitude $(\mathrm{p}<0.05)$. Mild headache and fatigue were invariably present, causing the Lake Louise score to increase to a diagnosis of mild acute mountain sickness (table 3). However, none of the subjects felt that these symptoms were serious enough to affect their exercise capacity. Chronic hypobaric hypoxia, as compared to acute normobaric hypoxia, was associated with similar effects on haemodynamics and oxygenation, with, however, higher $\mathrm{Sp}, \mathrm{O}_{2}$ and $\mathrm{BP}(\mathrm{p}<0.01)$, and slightly lower Q (tables 1 and 3). The TAPSE was unchanged, at $31 \pm 2 \mathrm{~mm}$ at sea level and $29 \pm 1 \mathrm{~mm}$ at altitude $(\mathrm{p}>0.05)$ but the Tei index increased from $0.21 \pm 0.05$ at sea level to $0.27 \pm 0.03$ at high altitude $(\mathrm{p}<0.05)$.

The CPET measurements were similarly affected in acute and chronic hypoxia, with however more important decreases of the maximum values of $V^{\prime} \mathrm{O}_{2}$, workload and $\mathrm{HR}$, as well as of $V^{\prime} \mathrm{O}_{2}$ at the anaerobic threshold, while maximum $\mathrm{O}_{2}$ pulse was not different, and maximum $V^{\prime} \mathrm{E}$ and $V^{\prime} \mathrm{E} / V^{\prime} \mathrm{CO}_{2}$ at the anaerobic threshold were increased. The RER and $S \mathrm{p}, \mathrm{O}_{2}$ were not different at maximum exercise capacity.

\section{Effects of sitaxsentan on CPET and haemodynamics}

At sea level, sitaxsentan slightly decreased BP in normoxia, decreased systolic $P$ pa, $\bar{P}_{\mathrm{pa}}, \mathrm{PVR}$ and Tei index in hypoxia 


\begin{tabular}{|c|c|c|c|c|}
\hline $\begin{array}{ll}\text { BLE } 3 & \text { Effec } \\
& \text { oxyg }\end{array}$ & $\begin{array}{l}\text { sitaxsen } \\
\text { aturation }\end{array}$ & in 22 subje & ects at hig & $\begin{array}{l}\text { hics and } \\
\text { y altitude }\end{array}$ \\
\hline \multirow[t]{2}{*}{ Variables } & \multicolumn{2}{|c|}{ Placebo group $\#$} & \multicolumn{2}{|c|}{ Sitaxsentan group ${ }^{\#}$} \\
\hline & Baseline & Placebo & Baseline & Sitaxsentan \\
\hline LL score & $7 \pm 2$ & $8 \pm 2$ & $8 \pm 2$ & $5 \pm 1^{*}$ \\
\hline $\mathrm{Sp}_{\mathrm{p}, \mathrm{O}_{2}} \%$ & $83 \pm 1$ & $86 \pm 1$ & $80 \pm 1$ & $83 \pm 1$ \\
\hline $\mathrm{BP} \mathrm{mmHg}$ & $98 \pm 3$ & $99 \pm 3$ & $102 \pm 2$ & $95 \pm 3^{*}$ \\
\hline HR beats $\cdot \min ^{-1}$ & $64 \pm 5$ & $64 \pm 4$ & $71 \pm 4$ & $74 \pm 4$ \\
\hline$Q L \cdot \min ^{-1}$ & $5.6 \pm 0.4$ & $5.7 \pm 0.4$ & $5.4 \pm 0.2$ & $6.3 \pm 0.4^{\star}$ \\
\hline Systolic Ppa mmHg & $38 \pm 2$ & $36 \pm 3$ & $37 \pm 1$ & $31 \pm 2^{\star}$ \\
\hline $\bar{P}$ pa $\mathrm{mmHg}$ & $25 \pm 1$ & $24 \pm 2$ & $24 \pm 1$ & $21 \pm 1^{*}$ \\
\hline PVR $\mathrm{mmHg} \cdot \mathrm{L}^{-1} \cdot \mathrm{min}^{-1}$ & $4.6 \pm 0.3$ & $4.3 \pm 0.4$ & $4.6 \pm 0.2$ & $3.5 \pm 0.2^{\star \star \star}$ \\
\hline Tei index & $0.28 \pm 0.04$ & $0.35 \pm 0.05^{\star}$ & $0.25 \pm 0.02$ & $0.27 \pm 0.04$ \\
\hline TAPSE cm & $3.1 \pm 0.1$ & $2.8 \pm 0.1^{*}$ & $2.8 \pm 0.1$ & $2.9 \pm 0.1$ \\
\hline \multicolumn{5}{|c|}{$\begin{array}{l}\text { Data are presented as mean } \pm \text { SE. LL: Lake Louise; } \mathrm{Sp}, \mathrm{O}_{2} \text { : arterial oxygen } \\
\text { saturation measured by pulse oximetry; BP: blood pressure; HR: heart rate; } \mathrm{Q} \text { : } \\
\text { cardiac output; Ppa: pulmonary artery pressure; } \bar{P} \text { pa: mean Ppa; PVR: pulmonary } \\
\text { vascular resistance; TAPSE: tricuspid annular plane systolic excursion. } \\
\#: \mathrm{n}=11 ;{ }^{*}: \mathrm{p}<0.05 \text {, sitaxsentan or placebo intake compared with baseline; } \\
\star *: \mathrm{p}<0.01 \text {, sitaxsentan or placebo intake compared with baseline; } \\
\star \star *: p<0.001 \text {, sitaxsentan or placebo intake compared with baseline. }\end{array}$} \\
\hline
\end{tabular}

(table 1), and improved $V^{\prime} \mathrm{O}_{2}$, max and maximum workload in hypoxia without other effects on CPET variables (table 2).

At high altitude, sitaxsentan improved the Lake Louise score, decreased BP, systolic P pa, $\bar{P}_{\text {pa }}$ and PVR, increased $\mathrm{Q}$, and prevented the decrease in TAPSE and increase in Tei index that occurred with 1 week of placebo intake (table 3). Sitaxsentan affected CPET variables by increases in maximum values of

\begin{tabular}{|c|c|c|c|c|}
\hline TABLE 4 & $\begin{array}{l}\text { sitaxse } \\
\text { yariable }\end{array}$ & $\begin{array}{l}\text { tan on car } \\
\text { in } 22 \text { subj }\end{array}$ & $\begin{array}{l}\text { rdiopulmo } \\
\text { eects at hig }\end{array}$ & $\begin{array}{l}\text { nary } \\
\text { gh altitude }\end{array}$ \\
\hline \multirow[t]{2}{*}{ Variables } & \multicolumn{2}{|c|}{ Placebo group ${ }^{\#}$} & \multicolumn{2}{|c|}{ Sitaxsentan group ${ }^{\#}$} \\
\hline & Baseline & Placebo & Baseline & Sitaxsentan \\
\hline Wor & $148 \pm 12$ & $151 \pm 13$ & $152 \pm 10$ & $167 \pm 13^{*}$ \\
\hline$V^{\prime} \mathrm{O}_{2}, \max \mathrm{mL} \cdot \mathrm{kg}^{-1} \cdot \mathrm{min}^{-1}$ & $27 \pm 2$ & $27 \pm 2$ & $27 \pm 1$ & $29 \pm 1^{*}$ \\
\hline$V^{\prime} E \max L \cdot \min ^{-1}$ & $118 \pm 13$ & $115 \pm 10$ & $128 \pm 11$ & $132 \pm 14$ \\
\hline RER max & $1.13 \pm 0.03$ & $1.12 \pm 0.02$ & $1.22 \pm 0.03$ & $1.15 \pm 0.03^{\star *}$ \\
\hline HR max beats $\min ^{-1}$ & $142 \pm 7$ & $135 \pm 8$ & $159 \pm 6$ & $153 \pm 6$ \\
\hline $\mathrm{O}_{2}$ pulse $\mathrm{mL} \cdot$ beat $^{-1}$ & $12 \pm 1$ & $13 \pm 1^{*}$ & $12 \pm 1$ & $13 \pm 1^{*}$ \\
\hline$V^{\prime} O_{2}$ at $A T L \cdot m^{-1}$ & $18 \pm 3$ & $19 \pm 2$ & $20 \pm 1$ & $21 \pm 1^{*}$ \\
\hline$V^{\prime} E / V^{\prime} \mathrm{CO}_{2}$ at $A T$ & $50 \pm 3$ & $52 \pm 2$ & $47 \pm 2$ & $48 \pm 1$ \\
\hline Exercise $\mathrm{Sp}, \mathrm{O}_{2} \%$ & $78 \pm 2$ & $78 \pm 2$ & $77 \pm 2$ & $77 \pm 2$ \\
\hline
\end{tabular}

Data is presented as mean $\pm \mathrm{SE}$. max: maximum; $V^{\prime} \mathrm{O}_{2}$,max: maximum oxygen uptake; $V^{\prime} E$ : minute ventilation; RER: respiratory exchange ratio; HR: heart rate; AT: anaerobic threshold; $V^{\prime} \mathrm{CO}_{2}: \mathrm{CO}_{2}$ output; $\mathrm{Sp}, \mathrm{O}_{2}$ : arterial oxygen saturation measured by pulse oximetry. ${ }^{*}: n=11 ; *: p<0.05$, sitaxsentan or placebo intake compared with baseline; ${ }^{*}: p<0.01$, sitaxsentan or placebo intake compared with baseline.

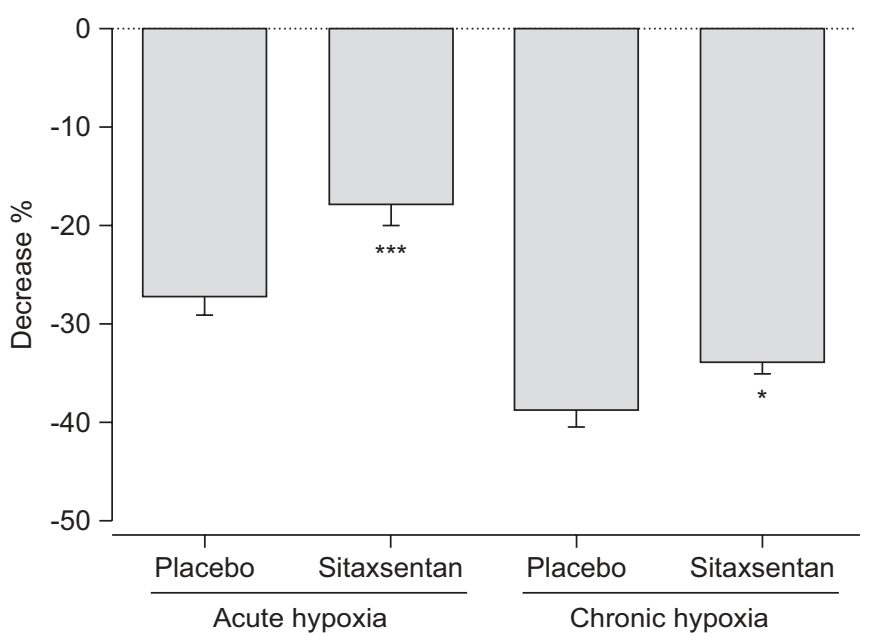

FIGURE 1. Mean \pm SE decrease in maximum oxygen uptake $\left(V^{\prime} \mathrm{O}_{2}\right.$, max $)$ induced by acute hypoxia and chronic hypoxia compared to sea-level value with and without sitaxsentan treatment. Sitaxsentan restored the hypoxia-induced decrease in $V^{\prime} \mathrm{O}_{2}$, max by approximately one-third in acute hypoxic conditions and by $12 \%$ during a stay at high altitude. *: $p<0.05 ;{ }^{*} *$ : $p<0.001$.

workload, $\mathrm{VO}_{2}, \mathrm{O}_{2}$ pulse and $\mathrm{VO}_{2}$ at the anaerobic threshold, while only $\mathrm{O}_{2}$ pulse increased after one week of placebo intake (table 4).

Sitaxsentan limited hypoxia-induced decrease in $V^{\prime} \mathrm{O}_{2}$, max, by an average of $30 \%$ in acute hypoxia and $10 \%$ in chronic hypoxia ( $\mathrm{p}<0.001$ and $\mathrm{p}<0.05$, respectively) (fig. 1). There was a significant inverse correlation between changes in $V^{\prime} \mathrm{O}_{2}$, $\max$ and resting systolic $P$ pa in acute normobaric hypoxia as well as at high altitude (fig. 2).

\section{Effects of sitaxsentan and altitude on renal function}

Altitude exposure was associated with decreased $C_{c r}$, decreased $\mathrm{CH}_{2} \mathrm{O}$ that was out of proportion with the $\mathrm{Ccr}$ decrease (leading to more negative $\mathrm{C}_{2} \mathrm{O} / \mathrm{C}$ cr ratio), decreased fractional excretion of uric acid, and increased fractional excretion of sodium together with an increased urinary $\log 10$ $\mathrm{Na} / \mathrm{K}$, while urine flow rate was unchanged (table 5).

Sitaxsentan had no effect on these renal function variables, neither at sea level, nor at high altitude.

\section{DISCUSSION}

The present study suggests that moderate hypoxic pulmonary hypertension in healthy subjects is partly mediated by endothelin A receptor signalling, and that this contributes to decreased aerobic exercise capacity. The results also show that selective endothelin A receptor blockade does not affect renal function in healthy subjects at sea level or at high altitudes.

Circulating endothelin-1 has been previously shown to be increased at high altitudes, in relation to increased $P$ pa and decreased arterial blood oxygenation [10, 20]. Endothelin-1 appears to play a role in hypoxia-induced pulmonary hypertension. An increased expression of endothelin-1 and the endothelin A receptor has been reported in rats exposed to a $\mathrm{FI}, \mathrm{O}_{2}$ of 0.1 for $48 \mathrm{~h}$ [21], with addition of an overexpression of the endothelin $\mathrm{B}$ receptor after increase of the duration of the hypoxic exposure to 4 weeks [22]. Both selective endothelin A 


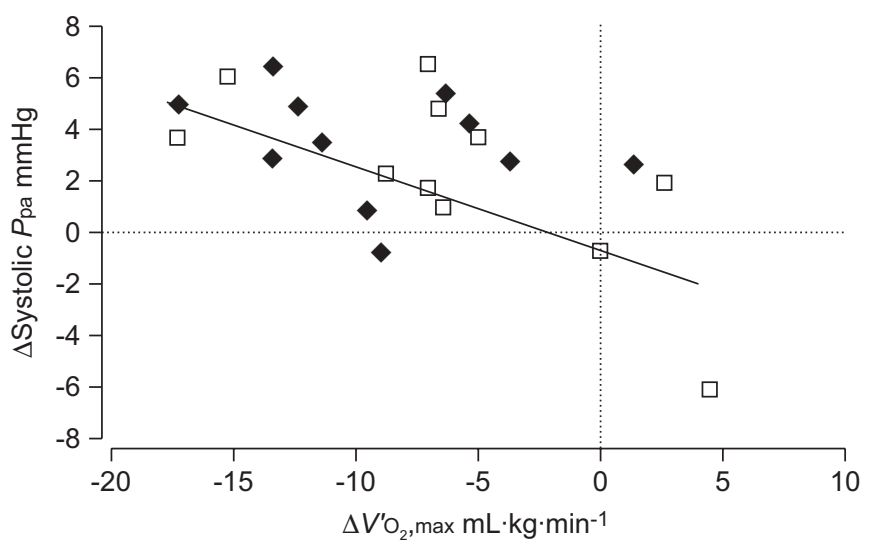

FIGURE 2. Correlation between systolic pulmonary artery pressure $(P$ pa) and maximum $\mathrm{O}_{2}$ uptake $\left(V^{\prime} \mathrm{O}_{2}\right.$, max $)$ in acute $(\bullet)$ and chronic $(\square)$ hypoxia. $r^{2}=0.33$ $p<0.01$.

and nonselective endothelin A and B receptor blockers prevent and reverse hypoxic pulmonary hypertension in experimental animals $[23,24]$. In healthy humans at high altitude, systolic $P$ pa is increased, and this has been shown to be partly reversed by the administration of the nonselective endothelin receptor antagonist bosentan [10]. A partial inhibition of normobaric hypoxic pulmonary vasoconstriction by the preventive intake of bosentan has been reported in healthy subjects [8]. In the present study, the effects of preventive sitaxsentan on normobaric hypoxic vasoconstriction were strikingly similar, suggesting little, if any, participation of endothelin B receptormediated release of vasodilating mediators or endothelin clearance [9]. The pulmonary vasodilating effects of sitaxsentan persisted during chronic exposure to hypobaric hypoxia, with partial reversal of hypoxia-induced increase in systolic $P$ pa and normalised PVR. Altogether, these observations suggest a major contribution of endothelin A receptor signalling in both acute hypoxic vasoconstriction and chronic hypoxic pulmonary hypertension in normal subjects acclimatised to high altitude.

Altitude exposure was associated with the expected decrease in aerobic exercise capacity [1,2]. The mechanisms of decreased exercise capacity associated with hypoxic exposure in healthy subjects are complex, with cardiovascular disturbances and more obvious decreases in arterial $\mathrm{O}_{2}$ content accounting for decreased $\mathrm{O}_{2}$ delivery to exercising muscles [1-3]. Recent observations of improved exercise capacity in hypoxia by pharmacologic interventions to decrease PVR, such as sildenafil $[4,5,7]$, dexamethasone [6], and bosentan [8], have raised the possibility of the participation of increased right ventricular afterload to limit $\mathrm{O}_{2}$ delivery to the tissues. This interpretation is supported by significant inverse correlations between changes in $V^{\prime} \mathrm{O}_{2}$, max and systolic $P$ pa, and better preservation of right ventricular function with unchanged TAPSE and Tei index after sitaxsentan intake in the present study. Both TAPSE and Tei index have been shown to be altered in pulmonary hypertension, in proportion to disease severity [17, 25]. Previous studies have shown maintained TAPSE and increased Tei index in lowlanders acclimatised to high altitudes, but comparably lower TAPSE and higher Tei index in high-altitude dwellers [26]. It is of interest that the improvement in $V^{\prime} \mathrm{O}_{2}$, $\max$ by sitaxsentan intake was less pronounced in chronic, as compared to acute hypoxic conditions, while PVR was higher, and still reversible. Our data offer no explanation for this observation, probably related to respiratory, cardiovascular or muscular adaptations over time.

We considered other possible explanations for sitaxsentaninduced improvement in $V^{\prime} \mathrm{O}_{2}$, max in the present study. Arterial oxygenation was unchanged at rest or during exercise. This argues against an improvement in pulmonary gas exchange, as was observed with the administrations of sildenafil $[4,5,7]$ or dexamethasone [6]. Maximum ventilation and ventilatory equivalents for $\mathrm{CO}_{2}$ were unchanged. This excludes a significant change in chemosensitivity, consistent with a previous report of unchanged chemosensitivity by bosentan intake in healthy subjects [27]. Maximum RER was unchanged, which argues against a central effect, which has been suggested as a potential mechanism of exercise capacity limitation in hypoxia [28]. Sitaxsentan slightly decreased BP and increased cardiac output, indicating a systemic vasodilating effect. This could have affected the distribution of systemic perfusion, which has been reported to be altered in hypoxia [2]. Selective endothelin antagonist-mediated increases in nitric oxide availability [9] could improve mitochondrial capacity by a protein kinase Gmediated pathway, thereby improving myocardial and skeletal

TABLE 5 Effects of sitaxsentan and of hypobaric hypoxia on renal function in healthy volunteers

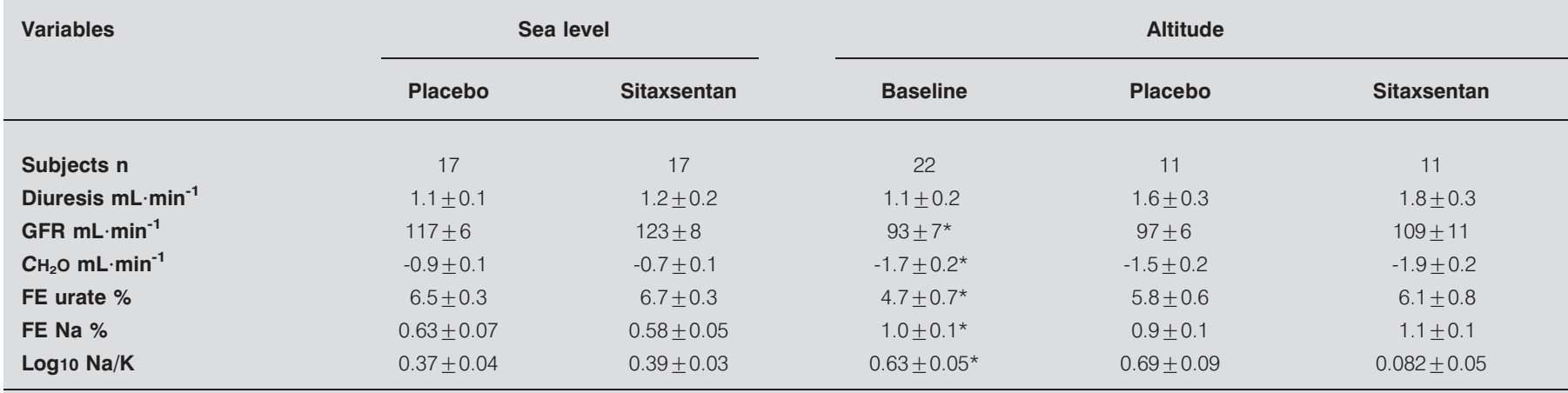

Data are presented as mean \pm SE. GFR: glomerular filtration rate; $\mathrm{CH}_{2} \mathrm{O}$ : free water clearance; FE: fractional excretion; Na: urinary sodium; $\mathrm{K}$ : urinary potassium. *: $\mathrm{p}<0.05$ altitude versus sea level. 
$\mathrm{O}_{2}$ uptake $[29,30]$. Thus, sitaxsentan could also have affected the matching of convectional and diffusional oxygen transport systems, which have been modelled to occur at a lower Q in hypoxia [3]. In the present study, there were renal function changes suggestive of decreased effective plasma volume, but this was unaffected by sitaxsentan, which indirectly argues against systemic changes in plasma volume to account for improved $\mathrm{O}_{2}$ delivery.

In the present study, renal function was evaluated by $C_{c r}$ to estimate GFR, $\mathrm{CH}_{2} \mathrm{O} / \mathrm{C}$ cr to estimate the effects of antidiuretic hormone (ADH) on collecting duct handling of water, fractional excretion of sodium (FE Na) and $\log 10 \mathrm{Na} / \mathrm{K}$ to evaluate the effects of aldosterone on collecting duct handling of sodium, and FE urate as an index of effective plasma volume [31]. Highaltitude exposure has been repeatedly shown to be associated with increased diuresis and natriuresis, and secondary haemoconcentration with decreased effective plasma volume [32, 33]. These effects are essentially related to decreased ADH and aldosterone signalling at the collecting ducts $[32,33]$. Healthy volunteers rapidly brought to the altitude of $4,559 \mathrm{~m}$ typically presented with increased diuresis, $\mathrm{CH}_{2} \mathrm{O} / \mathrm{GFR}$ and $\mathrm{FE} \mathrm{Na}$, in keeping with decreased renal tubular actions of both $\mathrm{ADH}$ and aldosterone [10]. However, these effects may vary over time, and are modulated by exercise and/or acute mountain sickness symptomatology $[33,34]$. In the present study, renal function tests were suggestive of relative hypovolaemia, as assessed by decreases in both $\mathrm{C}_{\mathrm{cr}}$ and $\mathrm{FE}$ urate, decreased $\mathrm{CH}_{2} \mathrm{O} / \mathrm{Ccr}$ suggestive of increased effects of $\mathrm{ADH}$, and increased $\mathrm{FE} \mathrm{Na}$ and $\log 10 \mathrm{Na} / \mathrm{K}$ suggestive of decreased effects of aldosterone. The diuresis was unchanged compared to sea level, in keeping with time taken for acclimatisation, and achieve new steadystate. Persistently decreased aldosterone signalling is consistent with previous observations [33]. Increased ADH signalling in the present study may be either time-related or associated with hiking activities and mild high-altitude sickness.

Endothelin-1 is locally produced by the kidney and exerts endothelin A receptor-mediated vasoconstrictive effects together with endothelin $B$ receptor-mediated inhibition of both ADH and aldosterone at the collecting duct $[35,36]$. In healthy subjects exposed to $4,559 \mathrm{~m}$, bosentan decreased $\mathrm{CH}_{2} \mathrm{O}$ corrected for GFR, with no significant effect on GFR or FE Na, strongly suggesting predominant effects of endothelin- 1 on the renal handling of water [10]. In the present study, sitaxsentan had no effect on indices of renal handling of water or sodium, consistent with the notion that the renal tubular effects of endothelin-1 are essentially B receptor-mediated [10, 35, 36]. Sitaxsentan intake was not associated with the increased GFR that could be expected on the basis of endothelin A receptor control of renal vascular resistance and renal vasodilating effects of endothelin B receptor-mediated nitric oxide and prostacyclin release $[35,36]$. However, there might have been a trend, as assessed by a 10\% increase in Ccr that did not reach significance.

Limitations of the present study include the noninvasive echocardiographic estimations of $\mathrm{Ppa}$ and cardiac output. However, we previously reported satisfactory interobserver and intraobserver variabilities on these measurements [26]. A good agreement between invasive and non invasive measurements of systolic $P$ pa has been previously reported at high altitude [37]. A more important limitation is the absence of echocardiographic measurements during exercise. This was attempted, but did not produce sufficiently high quality signals, in spite of encouragements to the volunteers to increase fluid intake before the examination, such as to avoid effects of dehydration. Thus, our results only indirectly support the notion that increased systolic $P$ pa limited $\mathrm{VO}_{2}$ max by a decrease in maximal cardiac output. Iit must be stressed that increased systolic $P$ pa would only partly contribute to hypoxiarelated decrease in aerobic exercise capacity, as supported by the $\mathrm{r}^{2}$-value of the correlation between changes in systolic $P$ pa and $V^{\prime} \mathrm{O}_{2}$, max of only 0.33 , suggesting that one-third of $V^{\prime} \mathrm{O}_{2}$, max changes could possibly be explained by changes in systolic $P$ pa. Furthermore, remote, high-altitude conditions prevented measurements of haematocrit and haemoglobin in all the subjects before and after intake of sitaxsentan, such that changes in arterial $\mathrm{O}_{2}$ content associated with the intake of the drug could not be excluded. It may be added that, in the absence of arterial blood-gas analysis, uncertainty remains about the validity of pulse oximetry estimations of arterial blood $\mathrm{O}_{2}$ saturations. Finally, there were no direct measurements of renal function or circulating hormones.

Sitaxsentan intake was associated with an unexpected decrease in maximum RER in hypoxia. We have no explanation for this effect, which was already observed with the intake of bosentan [8]. In addition, the intake of sitaxsentan was associated with an improved acute mountain sickness score. This may possibly be related to the cytoprotective effects of endothelin A receptor blockade reported in hypoxic astrocytes [38] or improved cerebral haemodynamics and oxygenation [39].

\section{SUPPORT STATEMENT}

This research was supported by the Everest-K2 National Research Council (Ev-K2-CNR) Project in collaboration with the Nepal Academy of Science and Technology as required by the Memorandum of Understanding between Nepal and Italy, and thanks to contributions from the Italian National Research Council. The study was supported by a grant from Pfizer.

\section{STATEMENT OF INTEREST}

Statements of interest for R. Naeije, S. Huez and V. Faoro, and for the study itself, can be found at www.erj.ersjournals.com $/$ site $/ \mathrm{misc} /$ statements.xhtml

\section{ACKNOWLEDGEMENTS}

We are grateful to GE Healthcare Ultrasound (Diegem, Belgium) for the loan of the Vivid i. The assistance of R. Bastin (Dept of Cardiology, Erasme University Hospital, Brussels, Belgium), S. Boldingh (VU University Medical Center, Amsterdam, the Netherlands), S. Martinez (Laboratory of Physiology, Faculty of Medicine, Free University of Brussels, Brussels, Belgium) and M. Moreels (Dept of Cardiology, Erasme University Hospital, Brussels, Belgium) was greatly appreciated.

\section{REFERENCES}

1 Fulco CS, Rock PB, Cymerman A. Maximal and submaximal exercise performance at altitude. Aviat Space Environ Med 1998; 69: 793-801.

2 Calbet JA, Boushel R, Radegran G, et al. Why is $V^{\prime} \mathrm{O}_{2}$, max after altitude acclimatization still reduced despite normalization of arterial $\mathrm{O}_{2}$ content? Am J Physiol Regul Integr Comp Physiol 2003; 284: R304-R316. 
3 Wagner PD. Reduced maximal cardiac output at altitude. Mechanisms and significance. Respir Physiol 2000; 120: 1-11.

4 Ghofrani HA, Reichenberger F, Kohstall MG, et al. Sildenafil increased exercise capacity during hypoxia at low altitudes and at mount Everest base camp: a randomized, double-blind, placebocontrolled crossover trial. Ann Intern Med 2004; 141: 169-177.

5 Fischler M, Maggiorini M, Dorschner L, et al. Dexamethasone but not tadalafil improves exercise capacity in adults prone to high altitude pulmonary edema. Am J Respir Crit Care Med 2009; 180: 346-352.

6 Richalet JP, Gratadour P, Robach P, et al. Sildenafil inhibits altitude-induced hypoxemia and pulmonary hypertension. Am J Respir Crit Care Med 2005; 171: 275-281.

7 Faoro V, Lamotte M, Deboeck G, et al. Effects of sildenafil on hypoxic exercise capacity in normal subjects. High Alt Med Biol 2007; 8: 155-163.

8 Faoro V, Boldingh S, Moreels M, et al. Bosentan decreases pulmonary vascular resistance and improves exercise capacity in hypoxia. Chest 2009; 135: 1215-1222.

9 Barst RJ. Sitaxsentan: a selective endothelin-A receptor antagonist, for the treatment of pulmonary arterial hypertension. Expert Opin Pharmacother 2007; 8: 95-109.

10 Modesti PA, Vanni S, Morabito M, et al. Role of endothelin-1 in exposure to high altitude: Acute Mountain Sickness and Endothelin-1 (ACME-1) study. Circulation 2006; 114: 1410-1416.

11 Yamaya Y, Boogard HJ, Wagner PD, et al. Validity of pulse oximetry during maximal exercise in normoxia, hypoxia, and hyperoxia. J Appl Physiol 2002; 92: 162-168.

12 Roach RC, Bärtsch $\mathrm{P}$, Hackett $\mathrm{PH}$, et al. The Lake Louise acute mountain sickness scoring system. In: Sutton JR, Houston CS, Coates G, eds. Hypoxia and Mountain Medicine. Burlington, Queen City, 1993; pp. 327-330.

13 Christie J, Sheldahl LM, Tristani FE, et al. Determination of stroke volume and cardiac output during exercise: comparison of twodimensional and Doppler echocardiography, Fick oximetry, and thermodilution. Circulation 1987; 76: 539-547.

14 Yock PG, Popp RL. Noninvasive estimation of right ventricular systolic pressure by Doppler ultrasound in patients with tricuspid regurgitation. Circulation 1984; 70: 657-662.

15 Chemla D, Castelain V, Humbert $M$, et al. New formula for predicting mean pulmonary artery pressure using systolic pulmonary artery pressure. Chest 2004; 126: 1313-1317.

16 Ghio S, Recusani F, Klersy C, et al. Prognostic usefulness of tricuspid annular planes systolic excursion in patients with congestive heart failure secondary to idiopathic or ischemic dilated cardiomyopathy. Am J Cardiol 2000; 85: 837-842.

17 Tei C, Dujardin K, Hodge D, et al. Doppler echocardiographic index for assessment of global right ventricular function. J Am Soc Echocardiogr 1996; 9: 838-847.

18 Wasserman K, Hansen JE, Sue DY, et al. Principles of Exercise Testing and Interpretation, 3rd Edn. Baltimore, Lippincott Williams and Wilkins, 1999; pp. 143-164.

19 Winer BJ, Brown DR, Michels KM. Statistical Principles in Experimental Design, 3rd Edn. New York, McGrall-Hill, 1991; pp. 220-283.

20 Goerre S, Wenk M, Bartsch P, et al. Endothelin-1 in pulmonary hypertension associated with high-altitude exposure. Circulation 1995; 91: 359-364.
$21 \mathrm{Li} \mathrm{H}$, Elton TS, Chen YF, et al. Increased endothelin receptor gene expression in hypoxic rat lung. Am J Physiol 1994; 266: L553-L560.

$22 \mathrm{Li} \mathrm{H}$, Chen SJ, Chen YF, et al. Enhanced endothelin-1 and endothelin receptor gene expression in chronic hypoxia. J Appl Physiol 1994; 77: 1451-1459.

23 Chen SJ, Chen IF, Meng QC, et al. Endothelin-receptor antagonist bosentan prevents and reverses hypoxic pulmonary hypertension in rats. J Appl Physiol 1995; 79: 2122-2131.

24 DiCarlo VS, Chen SJ, Meng QC, et al. ETA-receptor antagonist prevents and reverses chronic hypoxia-induced pulmonary hypertension in rat. Am J Physiol 1995; 269: L690-L697.

25 Forfia PR, Fisher MR, Mathai SC, et al. Tricuspid annular displacement predicts survival in pulmonary hypertension. Am J Respir Crit Care Med 2006; 174: 1034-1041.

26 Huez S, Faoro V, Guénard H, et al. Echocardiographic and tissue Doppler imaging of cardiac adaptation to high altitude in native highlanders versus acclimatized lowlanders. Am J Cardiol 2009; 103: 1605-1609.

27 Gujic M, Houssiere A, Xhaet O, et al. Does endothelin play a role in chemoreception during acute short term hypoxia in normal men. Chest 2007; 131: 1467-1472.

28 Kayser B. Exercise begins and ends in the brain. Eur J Appl Physiol 2003; 90: 411-419.

29 Nisoli E, Clementi E, Paolucci, et al. Mitochondrial biogenesis in mammals: the role of endogenous nitric oxide. Science 2003; 299: 896-899.

30 Mouchaers KT, Schalij I, Versteilen AM, et al. Endothelin receptor blockade combined with phosphodiesterase- 5 inhibition increases right ventricular mitochondrial capacity in pulmonary arterial hypertension. Am J Physiol Heart Circ Physiol 2009; 297: H200-H207.

31 Koeppen BM, Stanton BA. Renal Physiology, 2nd Edn. St Louis, Mosby, 1997.

32 Maresh CM, Kreaemer WJ, Judelson DA, et al. Effects of high altitude and water deprivation on arginine vasopressin release in men. Am J Physiol Endocrinol Metab 2004; 286: E20-E24.

33 Zacarria M, Rocco $\mathrm{S}$, Noventa $\mathrm{D}$, et al. Sodium regulating hormones at high altitude: basal and post-exercise levels. J Clin Endocrinol Metab 1998; 83: 570-574.

34 Loeppky JA, Icenogle MV, Maes D, et al. Early fluid retention and severe acute mountain sickness. J Appl Physiol 2005; 98: 591-597.

35 Kohan DE. Endothelins, renal tubule synthesis and actions. Clin Exp Pharmacol Physiol 1996; 23: 337-344.

36 Neuhofer W, Pittrow D. Endothelin receptor selectivity in chronic kidney disease: rationale and review of recent evidence. Eur J Clin Invest 2009; 39: 50-67.

37 Allemann Y, Sartori C, Lepori M, et al. Echographic and invasive measurements of pulmonary artery pressure correlate closely at high altitude. Am J Physiol Heart Circ Physiol 2000; 279: H2013-H2016.

38 Danielyan L, Gembizki O, Proksch B, et al. The blockade of endothelin A receptor protects astrocytes against hypoxic injury: common effects of BQ-123 and erythropoietin on the rejuvenation of the astrocyte population. Eur J Cell Biol 2005; 84: 567-579.

39 Schubert GA, Schilling L, Thomé C. Clazosentan, an endothelin receptor antagonist, prevents early hypoperfusion during the acute phase of massive experimental subarachnoid hemorrhage: a laser Doppler flowmetry study in rats. J Neurosurg 2008; 109: 1134-1140. 